\title{
A Design Insight for Substitution of Metal Shims with Reverse Engineered Element in Tool Post for Alignment of Tool-Work Center
}

Surabhi Lata* and Hitesh

Maharaja Agrasen Institute of Technology, Delhi, India

\begin{tabular}{|c|c|}
\hline ARTICLE INFO & ABSTRACT \\
\hline $\begin{array}{l}\text { Keywords: } \\
\text { Four Way Tool Post } \\
\text { Cutting tool height } \\
\text { adjustment } \\
\text { Screw thread analysis } \\
\text { least count calculations } \\
\text { Finite Element Analysis } \\
\text { CREO }\end{array}$ & $\begin{array}{l}\text { This research work propounds and analyses the comparison of } \\
\text { solution to the issue of height adjustment of tool in four way tool } \\
\text { post. The customary way of tool lifting in tool post to centre of work } \\
\text { i.e. by adding/removing metal packing, is altered by introducing a } \\
\text { design alternative for tool lifting, an upgradation in the former } \\
\text { proposed design named solid double cone threaded pin (SDCTP). It } \\
\text { is explicitly studied to investigate its limitation and scope for further } \\
\text { design amendments. In the premise, a revised design is proposed } \\
\text { including modifications named as solid cone threaded pin (SCTP) } \\
\text { and is fabricated along with its assembly. Mathematical calculations } \\
\text { of least count and screw thread analysis are performed on both the } \\
\text { pins. Finite element analysis on CREO is executed to calculate } \\
\text { stresses induced for diverse loads to analyze pin failure conditions. } \\
\text { The results of new modified design is compared with the erstwhile } \\
\text { concluding that SCTP design is preferable over SDCTP design } \\
\text { entailing precise tool adjustment, saving time and higher efficiency } \\
\text { in machining operations. The paper subsequently explores } \\
\text { conventional tool lifting method and its shortfall, shortcomings of } \\
\text { former design, revised design and its comparison, fabrication of } \\
\text { revised design, conclusions and future ambit. }\end{array}$ \\
\hline
\end{tabular}

\section{Introduction}

Every newfangled small and large scale manufacturing industries aspires to husband time and escalate production for the modernization of machinery. In every manufacturing workshop, the conventional lathe machine tool is an exigent machine tool on which turning, facing, tapering, knurling, grooving etc. operations are carried out. The time consuming problem confronted in all operations is the alignment of work piece center with the cutting tool tip. The existing way for aligning the tool tip held in the tool post to the work centre is achieved by the addition or subtraction of the metal packings or shims which is considered as a hit and trial and less accurate method. With the concept of reverse engineering, this paper moots the solution to this above mentioned predicament by introducing a design mechanism which expedites accurate alignment of tool tip with the workpiece along with the prevention of cutting tool tip from damage due to incorrect centering. Moreover the paper focuses on the meticulous study and comparison, design improvisation and engineering analyses of formerly proposed design namely solid double cone threaded pin (SDCTP) which results in prevalent of an upgraded or revised design namely as solid cone threaded pin (SCTP) concerning more precise tool adjustment and saving time which further leads to higher efficiency in machining operations.

* Corresponding Author E-Mail Address: lata.surabhi.8@gmail.com 


\section{Literature Review}

Ambati \& Rega (2013) developed a model which was able to predict the stress distributions, the cutting forces and the temperature on three different materials. It was also observed that the maximum stresses were more concerted in the tool tip which may lead to plastic deformation of edge of tool such as cracking. Patil \& Sarange (2014) presented a method to deduce tool forces, temperature distribution to determine stress distribution and deformation on the single point cutting tool. Increase in the tool forces due to high temperature generation was concluded as the main reason of tool failure. Rathod \&Razik (2014) investigated about heat generation in cutting tool which was carried out by altering cutting parameters at the apt cutting tool geometry. Lathwal \& Bhardwaj (2013) studied the effect of different rake angles on the force exerted on tool during cutting using FEM for chip formation mechanisms, heat generation in cutting zones, tool-chip interfacial frictional features. Bono \& Hibbard (2006) fabricated a tool holder used for sub- $\mu$ m positioning of a single point cutting tool on a fouraxis lathe equipped with a rotary table tool post to turn at any angle facilitating precision machining of meso-scale components with minimum increment of motion of $20 \mathrm{~nm}$. Harms et al. (2004) designed a tool holder for accurate placement of single point cutting tool to facilitate precision machining. An active tool adapter with built-in piezo actuator and force sensor for active vibration control was fabricated. Tiwari et al. (2014) proposed a design of a multi-purpose tool post aims at performing operations like drilling, milling, grinding. It involves a 3 phase electric motor kept parallel to lathe spindle axis mounted by bolts on the tool post and a small chuck is mounted on the shaft of that motor. Zhu et al. (2001) presented a technique for precision turning of shafts on conventional CNC turning centers. The precision motion of the tool is delivered using a fast tool piezo actuator which can be mounted on a conventional CNC lathe and which is controlled by the sliding mode controller. Haughton (2011) discussed about the description of the installation and use of a commercial quick change tool post on a personal tool room lathe. The 'rocker' tool posts \& boat shaped tool quick setting systems were initially used but failed as they lose their tool height setting when removed for tool re-sharpening. Sparber (2014) fabricated a tool post attachment for high speed rotary tool (Dremel holder for tool post). Holder was made from two pieces of cold rolled steel attached together with a pair of socket head screws. Novotny \& Blecha (2010) proposed an appraisal of design and risk analysis of a tool holder of vertical turning lathes and vertical machining centres, as here EMO: POWERTURN 2500 vertical CNC lathe. Rao et al. (2013) discussed and optimize the effect of cutting parameters on cutting forces and surface roughness during the turning operation on tool made of ceramic and work material of steel. Lalwani et al. (2007) investigated the effect of the cutting parameters on cutting forces and surface roughness in finish hard turning of MDN250 type steel using coated ceramic tool. Yaldiz et al. (2006) estimated the static and dynamic cutting forces with aid of piezoelectric accelerometer and strain gauges. Working parameters were cutting speed, feed \& DOC while response factors included feed force, thrust force and cutting force. Bhoyar \& Kamble (2013) build a FEA simulation model in order for obtaining the cutting forces, specific cutting energy and required temperatures arising at different points at the chip/tool contact region and the coating/substrate boundary for many cutting tool materials and also under different cutting conditions. It was concluded that tool wear causes increased cutting tool forces and surface temperature. At elevated cutting speed, cutting tool forces and surface temperatures decreased. Hou \& Jonesin (2000), Andriy Grytskiv et al. (2009) and Gunasekaran et al. (2014) documented the principle and working of ICP/OES and wet chemistry. It is used for the determination of trace elements in a diversity of sample matrices such as steels. This technique involves the spontaneous emission of photons and further the ions being excited in a radiofrequency (RF) discharge. Korka et al. (2013) experimentally studied the different types of forces which act on the tool during machining process along with the explanation of how these 
cutting forces vary with variation in feed rate, depth of cut and cutting speed. Yaldiz \& Unsacar (2007) fabricated a turning dynamometer which uses strain gauge and piezoelectric accelerometer to measure three perpendicular cutting force components of turning concurrently during turning while data acquisition system stores the measured numerical values in a computer. Vaxevanidis et al. (2013) presented an approach based on the design of experiments methodology and on the artificial neural networks for the modeling of the three component cutting force system during turning process of AISI D6 tool steel as cutting force calculation are important factors in metal cutting theory. Panzera et al. (2012) examined on the design, construction and testing features of a strain gauge dynamometer. It was developed to measure the three components of the force experienced during the turning operation. Kumar et al. (2012) determined the out-turn of the cutting parameters on forces produced in the turning operation on the conventional lathe machine tool involving the use of polycrystalline diamond (PCD) cutting tool on the composite material with various cutting conditions. Wang (2008) focused on the challenges faced during the application of reverse engineering in the verification and redesigning of the part. Reverse Engineering consist of two phases first decoding the original design details and then reproducing an identical counterpart. Batni et al. (2010) discussed the evaluation of the design of a mechanical component i.e. the crankshaft and its bearing and turbine blades with the help of reverse engineering. It included the reproduction of the existing object by analyzing its dimensions, features, form and properties. Kumar et al. (2014) defined reverse engineering in his research as the technology which develops CAD models of the existing design by capturing their surface data while rapid prototyping enables the fabrication of the physical prototype using an adaptive manufacturing technique. Rathore \& Jain (2014) reviewed the reverse engineering technique and its application areas. A detailed study has been carried out on the implementation of this process in the manufacturing industries. Reverse engineering has been defined as an approach for developing CAD model of a part in order to understand and analyze its design to further accommodate the new modifications. The model obtained thus can be used to remanufacture the part with improved functionality. Thompson et al. (1993) dealt with a prototype of a reverse engineering system using manufacturing features and described as the extraction of sufficient information about a part to replicate it with an appropriate manufacturing technique. Varady et al. (1996) discussed the reverse engineering process of shapes. The study involves algorithmic steps and reconstruction strategies which are discovered while analyzing any mechanical components based on their shapes.

\section{Tool Post and Tool Lifting Mechanisms}

\subsection{Traditional tool lifting mechanism and its shortcomings}

The lathe tool post is one of the essential parts of carriage which support and guide the cutting tool. It is mounted on top of the compound rest to firmly hold the cutting tools. Its location is on the top of the cross feed, which is mounted on the saddle which in turn fits over the bed and slides along the ways. It is thus possible to move the tool post in any direction depending upon the requirement (Lye, 2014). The four-way turret tool post is one of the most extensively used tool post in modern industrial centre lathes and is highly suitable for repetitious work. It is robust and can accommodate four tools at a time which can be quickly swung into position as required. The cutting tool is held in position by separate screws and a locking bolt is located at the centre (Timings, 2010). The 2D design of tool post and compound rest assembly available for the experimentation is shown below in Figure 1. The proper alignment of tool tip with the centre of the work is the most basic necessity during the machining operations performed on the lathe such as turning, facing, knurling, grooving etc. The conventional design for lifting the cutting tool in the tool post uses metal shims or metal packing. The 
adjustment of height of the tool can be done only by adding or removing the packing and the metal shims below the tool as depicted in Figure 1.

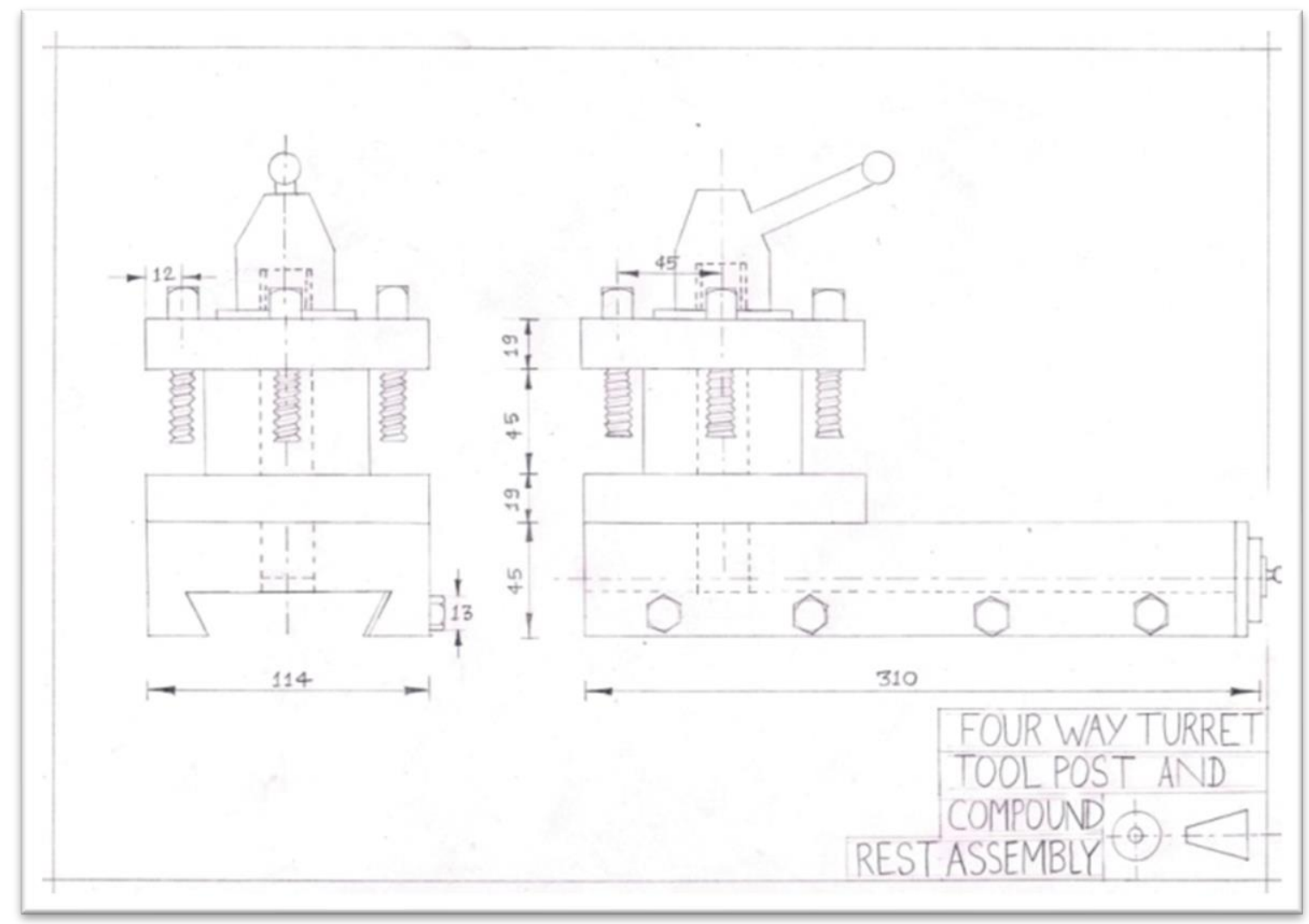

Figure 1. Design of four way tool post and compound rest

Too high base of the tool will exert force on the workpiece leading to damage to work as well as to the cutting tip. If tool is set too low, the tip will tend to gouge and/or cut too deep leaving an undesirable 'nub' on reaching the centre of the workpiece (Groover, 2007).

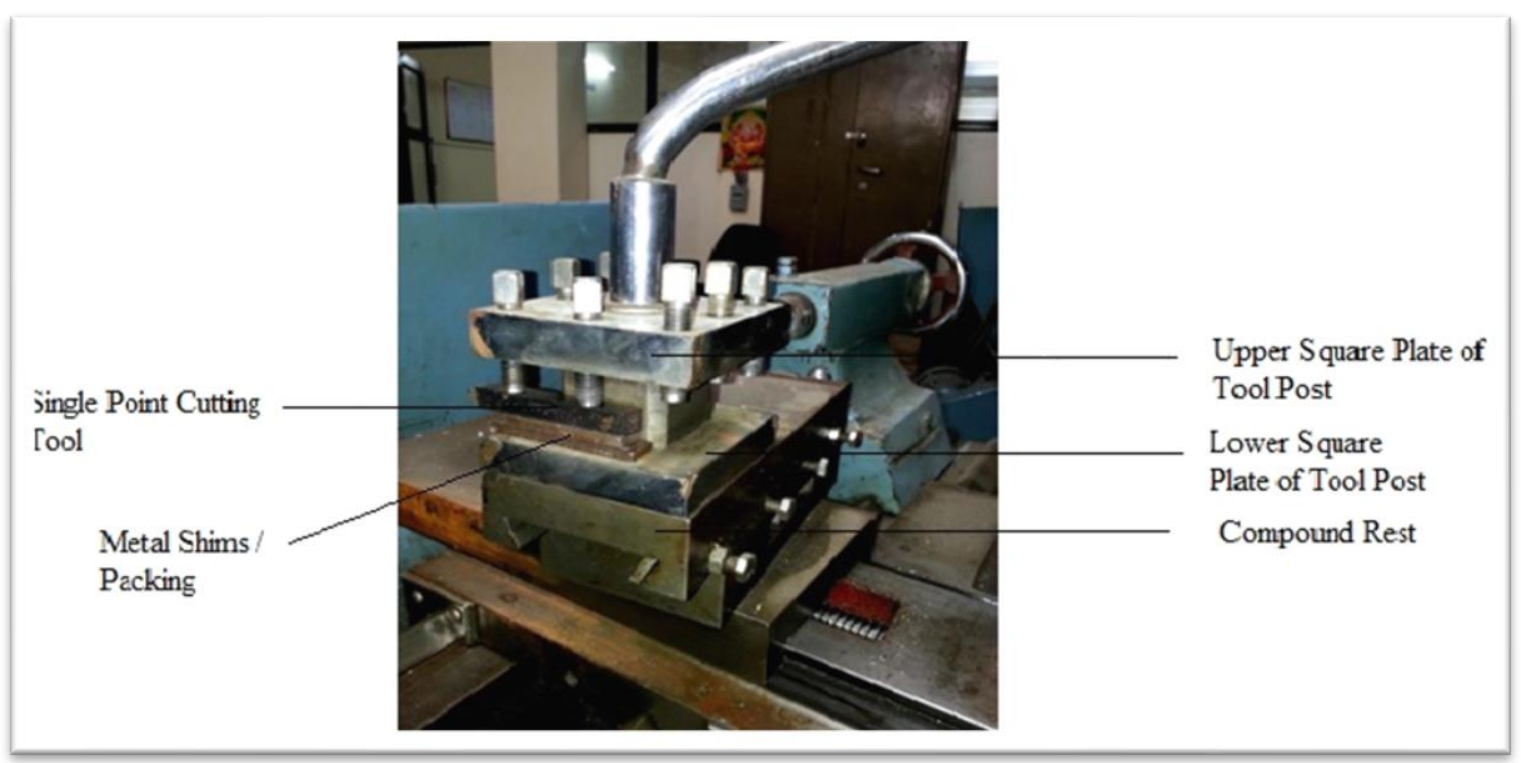

Figure 2. Tool post demonstrating the use of metal shims for lifting the cutting tool 
Number of packing or metal shims to be used, thickness of packing being used and alignment of tool tip with centre of the workpiece are the main features of the conventional method of tool lifting which is solely based on rough estimation. The height adjustment in a four way (turret) tool post is attained by an approximate method and therefore it is difficult to align the cutting tool tip with the axis of the workpiece. Hence, the way of lifting the cutting tool to the center of workpiece can be termed as a hit-and-trial method based on rough estimation. It is a time consuming and less accurate process and at times, it becomes laborious task to adjust the tool tip after every regrinding to the same level of accuracy.

\subsection{Redesigned Mechanized Element: Solid Double Cone Threaded Pin (SDCTP)}

The modification in the conventional four-way tool post design was the introduction of a threaded component named as solid double cone threaded pin (abbreviated as SDCTP) which was proposed to be placed in a rectangular cavity in between the lower square plate of the tool post and the compound rest (Kumar et al., 2015). The rectangular cavity is made such that it fits the designed component with suitable allowance. A fixed threaded length will always be in contact with the lower tool post plate and the part of compound rest. The proposed pin works on the principle of conversion of rotational motion into translation motion with the help of a nut and screw arrangement incorporating self-locking mechanism to avoid slip during the machining operations. When the solid cones (double identical frustums) are given rotational motion, the cylindrical bodies in contact with them will translate in vertical direction. The motion analysis of SDCTP is delineated by Figure 3.

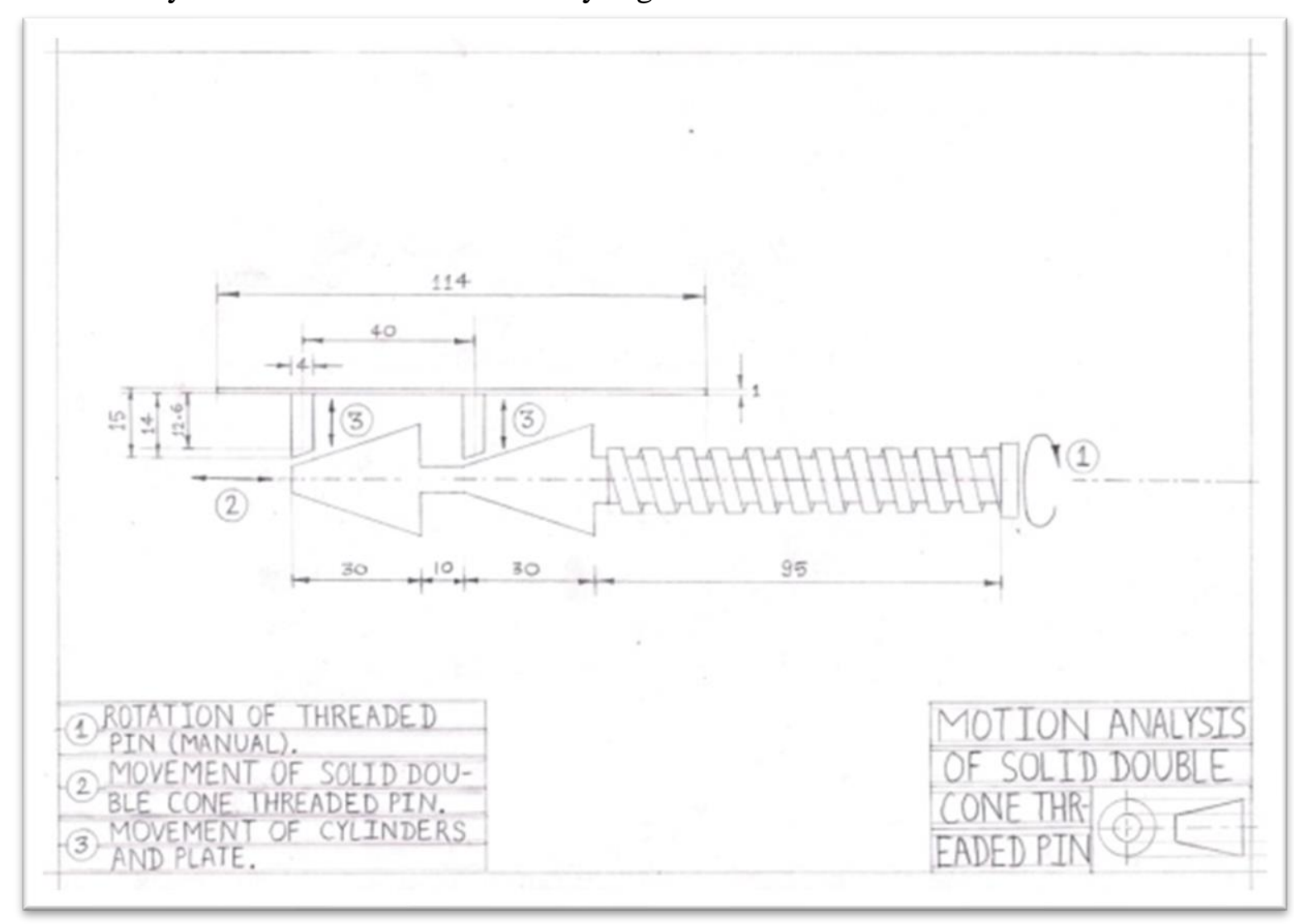

Figure 3. Formerly proposed design (SDCTP) depicting its motion

\subsection{Paucities Found in Erstwhile Proposed Design and Sites of Improvement}

In this design, the total load which was acting on the pin was transmitted to or shared by only two tapered cylinders that is at two points. There was also a restriction to place the two tapered cylinders $40 \mathrm{~mm}$ apart to accommodate the cutting tool. If the tool shank was smaller than 40 
$\mathrm{mm}$, high chances of slipping may arise during the machining process. Further, any variation in the dimension of the two identical frustums would lead to low surface finish and decreased dimensional accuracy due to imbalance of cutting tool. Most importantly the design was found to be critical in the region lying between the two frustums as the stress concentration might break the component during the machining process.

\section{Design Development of Modified Tool Lifting Mechanism}

\subsection{Modification of Mechanized Element: Solid Cone Threaded Pin (SCTP)}

The former design SDCTP was refined by carrying out three modifications to overcome its shortfalls. The major modification involved the replacement of two identical frustums by a single frustum. The revised single solid cone has a taper angle of $8.13^{\circ}$ instead of $18.43^{\circ}$ as that of in former design. This helped in improving the efficiency and eliminated the manufacturing anomaly. A transformation was done by adopting standard consideration for major diameter and pitch for threaded portion of pin. A standard major diameter M20 with coarse pitch $2.5 \mathrm{~mm}$ was implemented after analyzing their advantages and applications. Further refinement was the replacement of two tapered cylinders with three tapered cylinders over the same axial length of tapered portion of pin as the same total load is now being shared by three tapered cylinders i.e. at three points. The $2 \mathrm{D}$ design of solid cone threaded pin (abbreviated as SCTP) is showed in Figure 5. It also works on the principle of conversion of rotational motion into translation motion with the help of a nut and screw arrangement as the previous mechanized element SDCTP. The motion analysis of SCTP is delineated by Figure 5 .

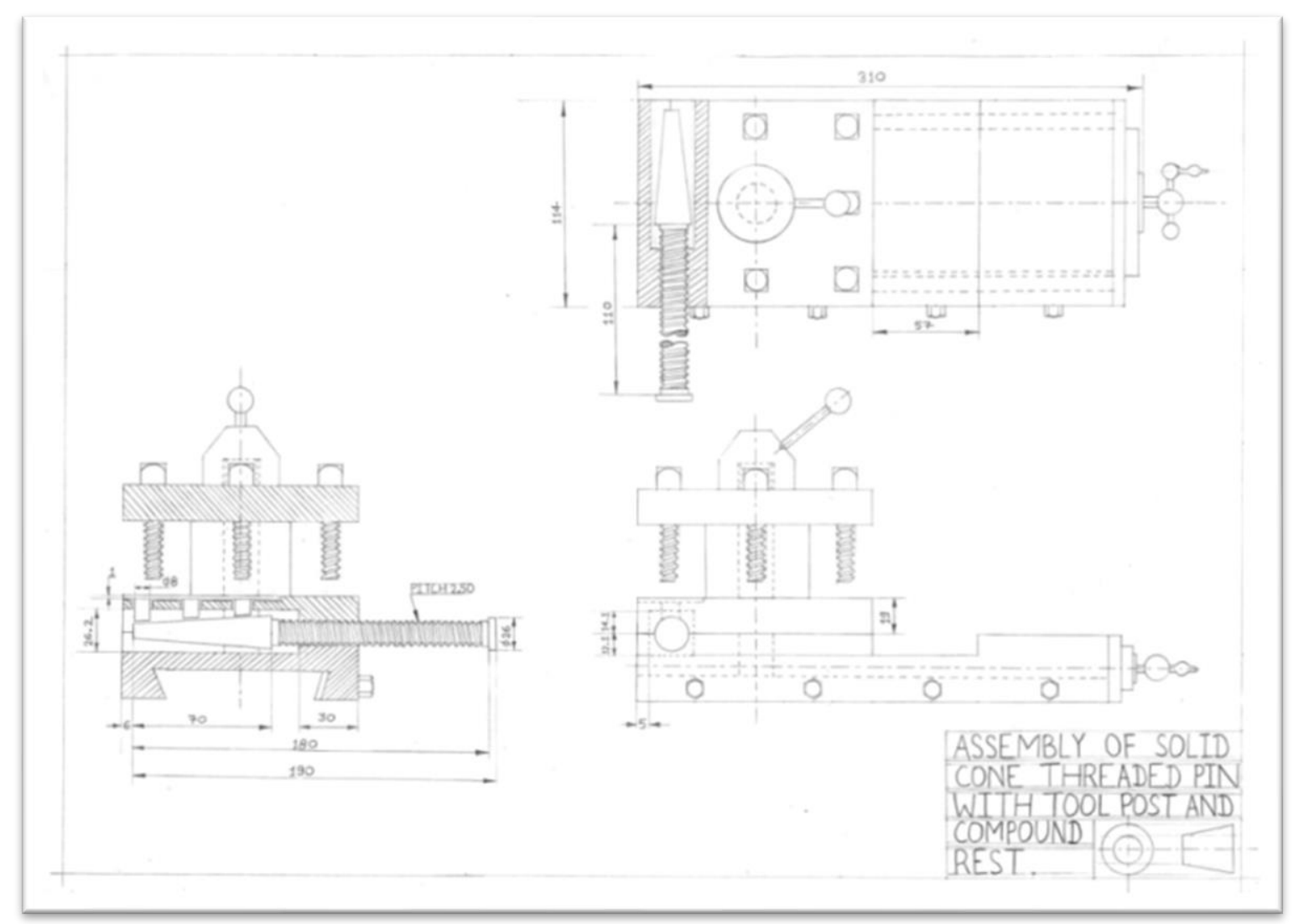

Figure 4. Design of four way tool post and compound rest with modified design (SCTP)

\subsection{Selection of Material}

The selection of material was carried out in order to design the component which can bear high developed stresses during the machining process. A complete detailed study was 
conducted such that the designed pin exhibit stable qualities, high wear resistance reliability and longevity during the service time (Ostwald \& Munoz, 2008 and Agrawal, 1988). According to the impact of environment and the running condition of the component, it was found that the component required material with high hardness, high fatigue strength and high abrasion resistance. These requirements and expectations of mechanical properties at an optimum economic level were fulfilled by high carbon chromium manganese steel of grade EN 31 which was conformed through spectro analysis prior manufacturing.

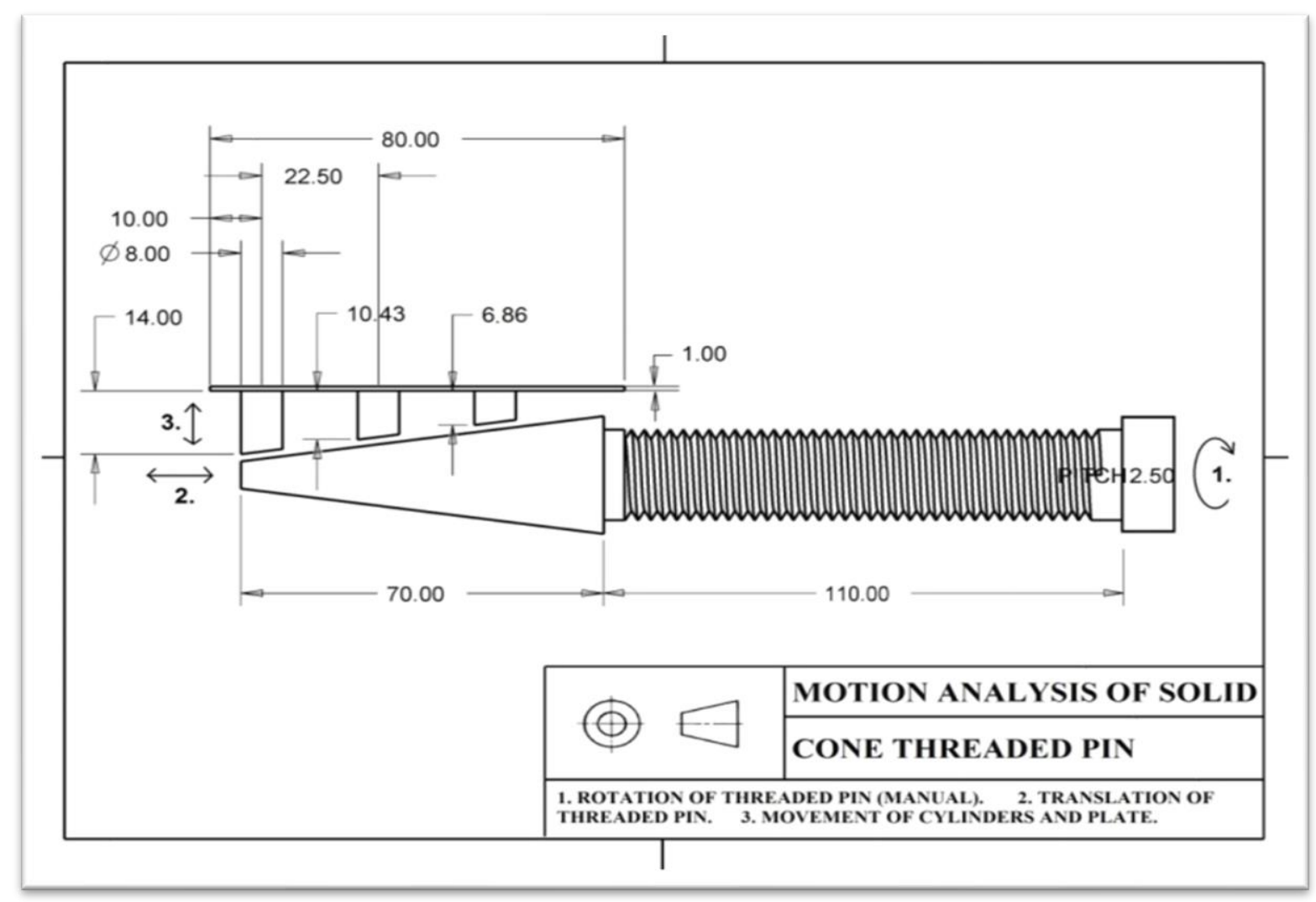

Figure 5. Modified proposed design (SCTP) depicting its motion

\section{Design Analysis of Modified Mechanized Element (SCTP)}

Engineering analysis is the internal guidance of the engineering design loop. It is defined as the breaking down of an object, system or problem into its basic elements to extract the essential features and their inter-relationships. The in-depth knowledge and extensive analysis prior to implementation help to attain high degree of safety under working conditions. The following sections will discuss the various analyses in detail.

\subsection{Least-Count Analysis}

In metrology, the least count of an instrument is the smallest change in the measure and distinguished on scale of the instrument. The least count is inversely proportional to the precision of the instrument. The analysis of the designed pin is carried out to realize the minimum uplift of the cutting tool when the pin actually intended for use (Nakra, 2013 and Wilson \& Hernandez-Hall, 2009). Consider the Figure 6 for this analysis.

From the geometry of the design shown above, taper angle ' $\theta$ ' is calculated as $8.13^{\circ}$. For one rotation, the designed pin will move $2.5 \mathrm{~mm}$ (pitch) forward axially to give an uplift of ' $\mathrm{x}$ ' $\mathrm{mm}$ to the cutting tool which is determined as $0.357 \mathrm{~mm}$. Now for proposed $10 \mathrm{~mm}$ uplift of the cutting tool by the designed pin, the number of rotations required are calculated 
implementing unitary methods. According to this, $1 \mathrm{~mm}$ axial movement of pin is achieved by 0.4 rotation of the pin. Therefore, $70 \mathrm{~mm}$ axial movement of pin i.e. the maximum uplift of tool is attained by 28 rotations of the pin. The total axial length covered by pin will be the axial length of taper part of the pin i.e. $70 \mathrm{~mm}$.

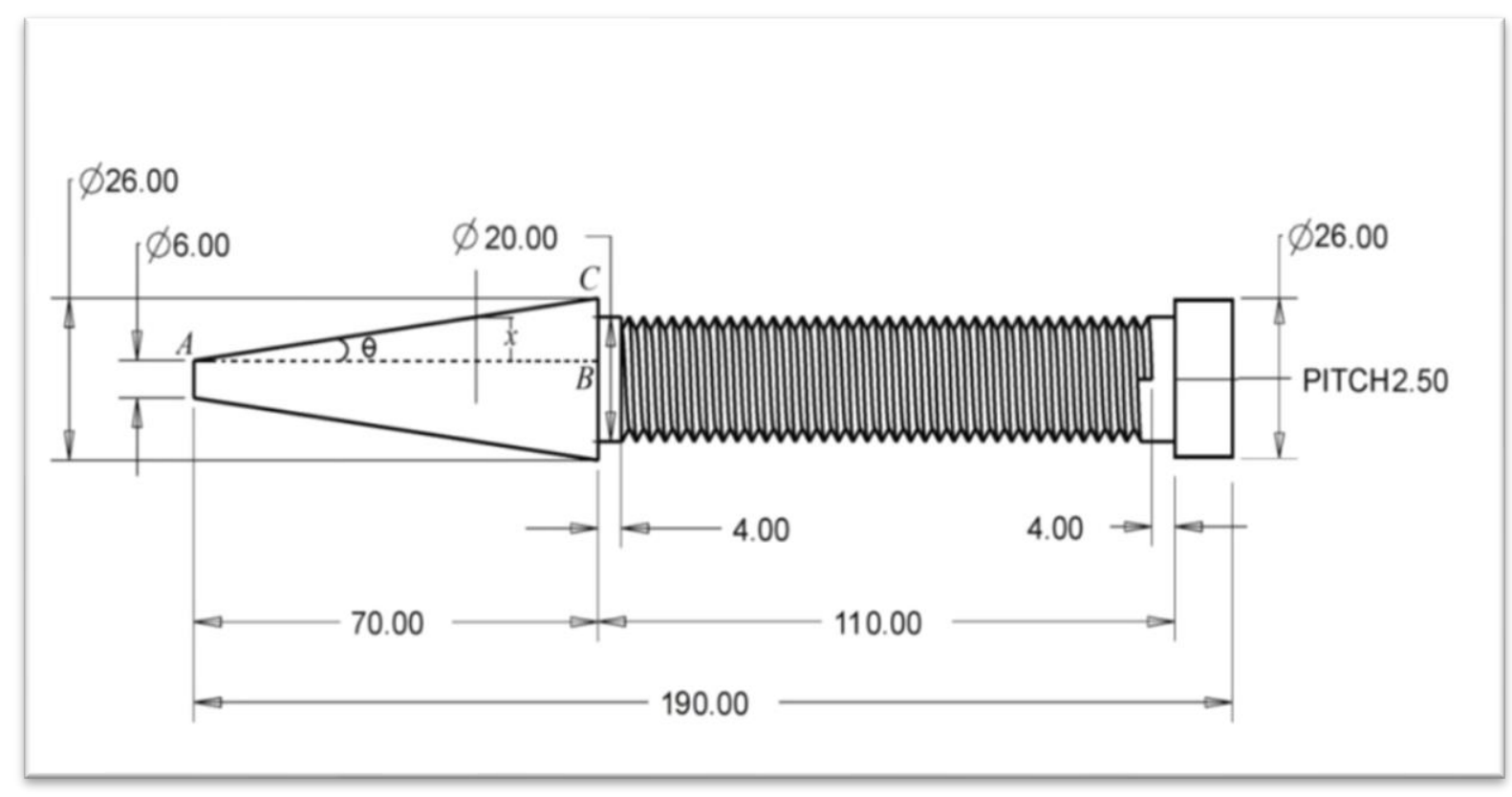

Figure 6. Diagrammatic representation of SCTP for calculations

If 1 rotation $\left(360^{\circ}\right)$ of pin will give $2.5 \mathrm{~mm}$ forward axial movement of pin (since pitch is 2.5 $\mathrm{mm}$ ) then, $5^{\circ}$ rotation of pin will give $34.7 \mu \mathrm{m}$ axial movement which is the minimum forward axial movement of pin. Also, the minimum uplift (or least count) for the cutting tool for 2.5 $\mathrm{mm}$ pitch is

$$
\frac{0.357}{72}=0.00495 \mathrm{~mm}=4.95 \mu \mathrm{m}
$$

\subsection{Thread Failure Analysis}

When the assumption of static load action on the pin is considered, coarse thread of $2.5 \mathrm{~mm}$ pitch are found to be suitable for the selected standard nominal diameter (D) of M20 (Atkins et al., 2013 and Bhandari, 2012). For a typical static bolted joint, the evaluation of three failure modes to determine the highest load that the bolted joint can withstand is performed further. These failure modes are tensile failure of the bolt body, shear failure of the bolt threads and shear failure of the internal threads (Jha, 2015). The amount of force required to break the bolt (designed pin in this case) in tension and shear are calculated below assuming factor of safety as 1 .

1. Tensile force required to break the bolt or pin, $\mathrm{P}_{t}=\mathrm{S}_{\mathrm{yt}} \times \mathrm{A}_{\mathrm{t}}=161.7 \mathrm{kN}$

Where, $S_{y t}=$ Yield strength in tension $\left(E N 31=660 \mathrm{~N} / \mathrm{mm}^{2}\right)\left(\right.$ Mahata, 2015) and $A_{t}=$ Tensile stress area of the bolt or pin $=245 \mathrm{~mm}^{2}$ (Jha, 2015).

2. Shearing force required to break the pin, $\mathrm{P}_{\mathrm{sb}}=\mathrm{S}_{\mathrm{sy}} \times \mathrm{A}_{\mathrm{sb}}=253.6 \mathrm{kN}$

where, $\mathrm{S}_{\mathrm{sy}}=$ Yield strength in shear for EN31 which is $57.7 \%$ of Syt, (Liu, 2005) $=380.8$ $\mathrm{N} / \mathrm{mm}^{2}, A_{\mathrm{sb}}=$ Shear stress area or stripping area of the bolt or pin $=33.3 \mathrm{Le}=20 \mathrm{~mm}$ and $\mathrm{L}_{\mathrm{e}}=$ Thread engagement length which is assumed one times the nominal bolt diameter (Blake, 1986).

3. Shearing force required to break the internal threads, $\mathrm{P}_{\mathrm{si}}=\mathrm{S}_{\mathrm{sy}} \times \mathrm{A}_{\mathrm{si}}=345.7 \mathrm{kN}$ where, $A_{\mathrm{si}}=$ Shear stress area or stripping area of internal threads $=45.4 \mathrm{Le}$ (Jha, 2015). 


\subsection{Finite Element Analysis}

In CREO, FEA of designed threaded pin is performed by applying point load on the pin. Von Mises stresses are induced and distributed over the region of application of these forces. According to Von Mises theory the design will fail if the maximum value of Von Mises stress induced in the material is more than the yield strength of the material which is $660 \mathrm{MPa}$ in this case (Mahata, 2015). The crucial point of considerations regarding FEA of the pin is emplacement and magnitude of loads acting on it. In actual working state of the pin, the positions of load action will change when size of workpiece changes but these positions will remain stationary during turning operation. However, the quantities of the turning forces reaching the stationary pin (through a plate and three cylinders) vary for each job according to the turning parameters.

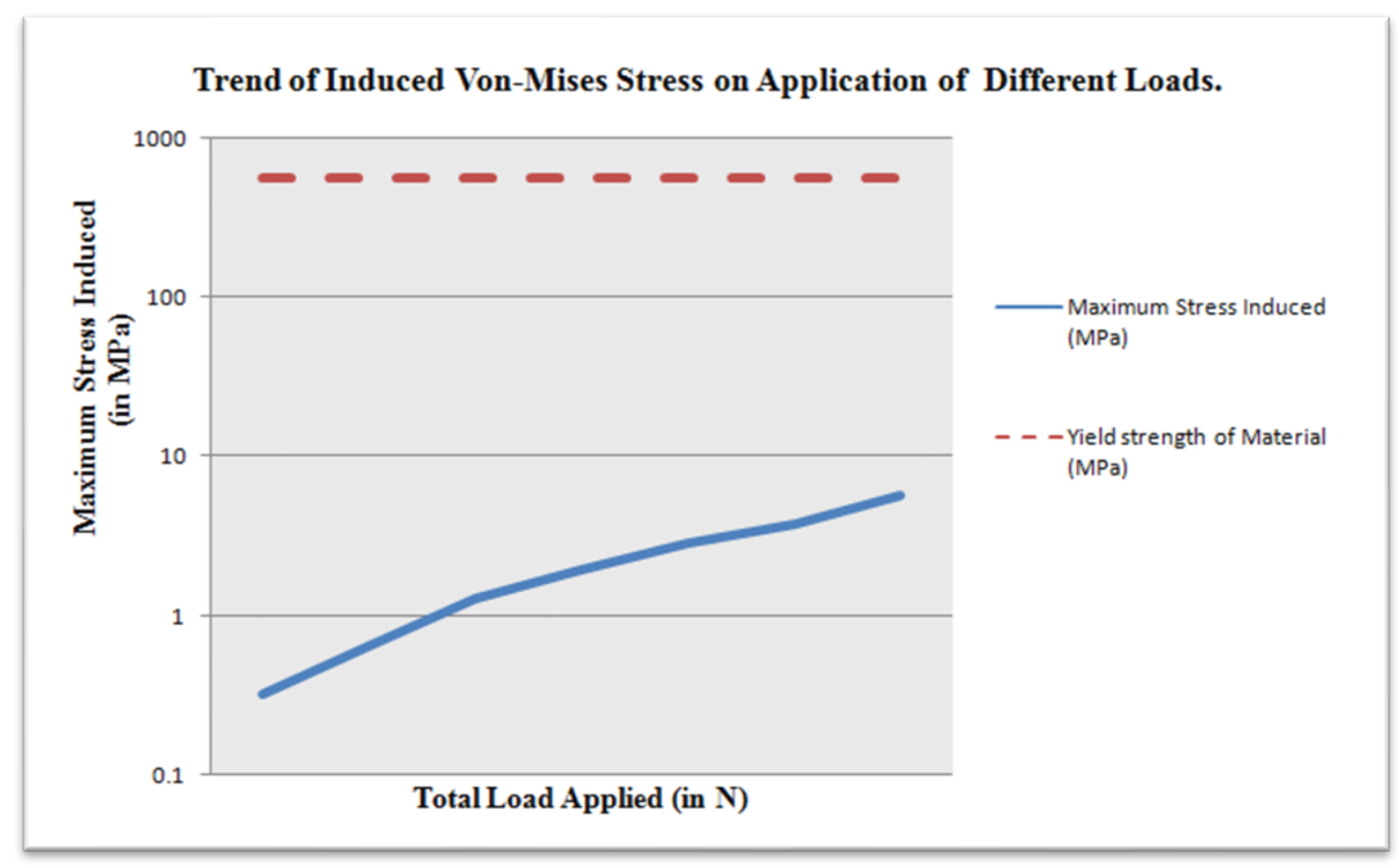

Figure 7. Trend of induced von Mises stress on application of different loads

In FEA the forces described above are taken in accordance to the conventional turning forces experienced by the cutting tool during the actual turning operation. For the development of the safe design, in FEA gradual higher forces are applied in order to seek critical regions or any chance of failure of pin during its working. A case of FEA for force of $12 \mathrm{kN}$ is shown and the values of its von Mises stress along with other cases has been tabulated under the result section. Further, a graph depicts the trend of induced Von Mises stress in the pin on application of different loads.

\section{Manufacturing of Modified Tool Post}

The manufacturing procedure included the material procurement, development of raw dimensions and eventually finishing operations to attain the final dimension of the modified tool post. The material was procured in the form of two square blocks of dimensions 116x116x15 mm $\mathrm{mm}^{3}$ and 116x116x25 $\mathrm{mm}^{3}$, one shaft of $28 \mathrm{~mm}$ diameter and $200 \mathrm{~mm}$ length, one shaft of $10 \mathrm{~mm}$ diameter and $60 \mathrm{~mm}$ length and one rectangular plate of dimension $80 \times 24 \times 4 \mathrm{~mm}^{3}$. 


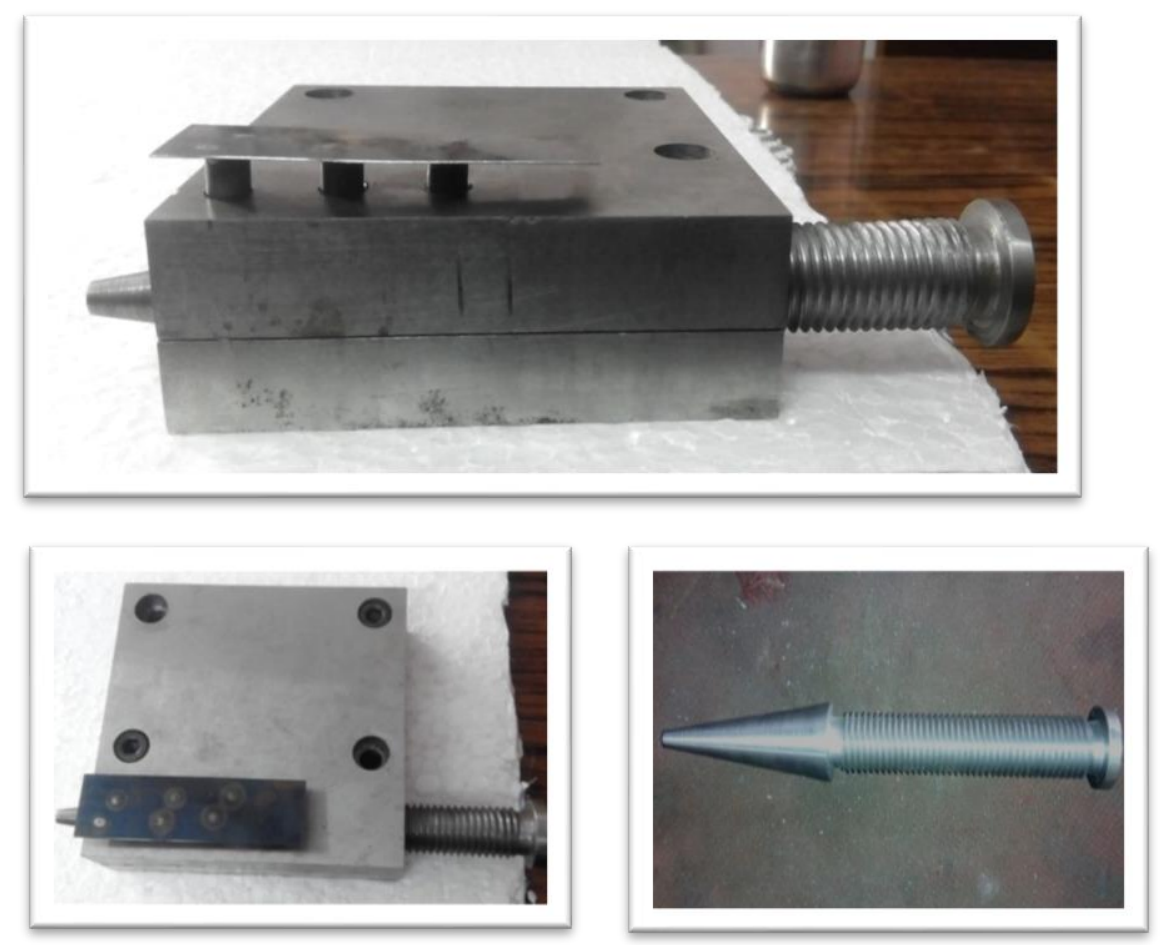

Figure 8. Fabricated solid cone threaded pin and its groove screwed assembly

The fabrication of assembly consisted of solid cone threaded pin, lower plate of tool post, upper part of compound rest, radial contoured cylinders and top plate. The assembly was locked and secured using the groove screws to eliminate any obstruction occurring in securing the tool. Apart from this, three radial contoured cylinders were fabricated which were welded to the top plate through GMAW process. The final assembly of tool post parts is illustrated in Figure 8.

\section{Results and Discussion}

\subsection{Summary of Result}

The change in design of the conventional tool post and compound rest assembly consisted of designing of a threaded pin. There were two designs which were analyzed in detail and further compared to identify the most suitable design owing to the working conditions of a lathe machine tool in manufacturing and production industries. The table below displays the distinction between former design named SDCTP and modified design named SCTP based on the software and mathematical analyses conducted on them.

Table 1.

Result comparison between former design and modified design

\begin{tabular}{lll}
\hline Parameters & $\begin{array}{l}\text { SDCTP } \\
\text { (Former Design) }\end{array}$ & $\begin{array}{l}\text { SCTP } \\
\text { (Modified Design) }\end{array}$ \\
Taper angle $\left(^{\circ}\right)$ & 18.43 & 8.13 \\
PCD of threads $(\mathrm{mm})$ & 12.4 & 18.3 \\
Pitch $(\mathrm{mm})$ & 4.00 & 2.50 \\
Least count or Minimum height upliftment $(\mu \mathrm{m})$ & 18.5 & 4.9 \\
Total no. of rotations possible & 8 & 28 \\
Length of engagement of screw threads $(\mathrm{mm})$ & 10.2 & 20 \\
Tensile force required for failure of pin $(\mathrm{kN})$ & 74.4 & 161.7 \\
Shear force required for failure of pin $(\mathrm{kN})$ & 89.5 & 253.6 \\
\hline
\end{tabular}


Table 2.

Result comparison between former design and modified design

\begin{tabular}{lcccc}
\hline \multirow{2}{*}{ Parameters } & \multicolumn{2}{c}{$\begin{array}{c}\text { SDCTP } \\
\text { (Former Design) }\end{array}$} & \multicolumn{2}{c}{$\begin{array}{c}\text { SCTP } \\
\text { (Modified Design) }\end{array}$} \\
\cline { 2 - 5 } & $\begin{array}{c}\text { Total Load } \\
(\mathrm{N})\end{array}$ & Stress (MPa) & $\begin{array}{c}\text { Total Load } \\
(\mathrm{N})\end{array}$ & $\begin{array}{c}\text { Stress } \\
(\mathrm{MPa})\end{array}$ \\
\hline & 500 & 0.3547 & 500 & 0.3175 \\
& 750 & 0.5321 & 750 & 0.6318 \\
Maximum Von-Mises stress during FEA & 1500 & 1.064 & 1500 & 1.264 \\
& 3000 & 2.128 & 3000 & 1.905 \\
& 4500 & 3.192 & 4500 & 2.858 \\
& 6000 & 4.257 & 6000 & 3.789 \\
& 9000 & 6.385 & 9000 & 5.684 \\
& 12000 & 8.513 & 12000 & 7.621 \\
\hline
\end{tabular}

\subsection{Discussion of Result Based on Mathematical Outputs}

In many aspects the former design (SDCTP) was enhanced to yield better efficiency in terms of cost and mechanical properties. In the modified design (SCTP), threads of standardized pitch of $2.5 \mathrm{~mm}$ with M20 major diameter has been used as compared to the threads used in the former design hence, making the modified design more compatible, inter-operable, safer and flexible. The changes also facilitated in improving the minimum cutting tool height upliftment or the least count. Based on the mathematical calculations, the SCTP is more robust in design as it will require more shear and tensile force as compared to SDCTP to fail through the threaded region. The previous requirement of minimum thread engagement was $10.2 \mathrm{~mm}$ which is now increased to $16.9 \mathrm{~mm}$ through improvisation and hence enhancing the stability of the pin in the assembly. In SDCTP square screw threads were considered to manufacture but to have an economical design instead of square, $60^{\circ} \mathrm{V}$-threads were manufactured in modified design (SCTP). While moving from SDCTP to SCTP, the tensile and shear failure loads also increases making the new design safer.

\subsection{Discussion of Result Based on FEA}

The tangential or cutting forces during turning operations are in orders of $1000 \mathrm{~N}$ (Korka et al., 2013). A case of FEA is compared in Figure 9 between two pins for the same total load applied i.e. $3000 \mathrm{~N}$. As inferred from the FEA conducted on both the pin designs, the anticipation of failure of the modified is more than the former about the critical cross-section of the pin. This failure is found to be prevalent due to the development of the stresses on and around the particular section where load is acting. Further, the same load of $3000 \mathrm{~N}$ is being equally distributed at two points on two frustums in former designed pin while in the modified pin it is distributed at three points on a single frustum. Similarly, during analysis and comparison among all other cases, it is found that stresses developed on the modified pin during machining process are less than that for former pin design and also less when compared to the yield strength of steel (i.e. $660 \mathrm{MPa}$ for EN 31). Hence, the design of the pin is feasible. It is clear, the trend of stresses from the graph shown in Figure 9 manifests the precedence of modified design i.e. SCTP over former design i.e. SDCTP. 

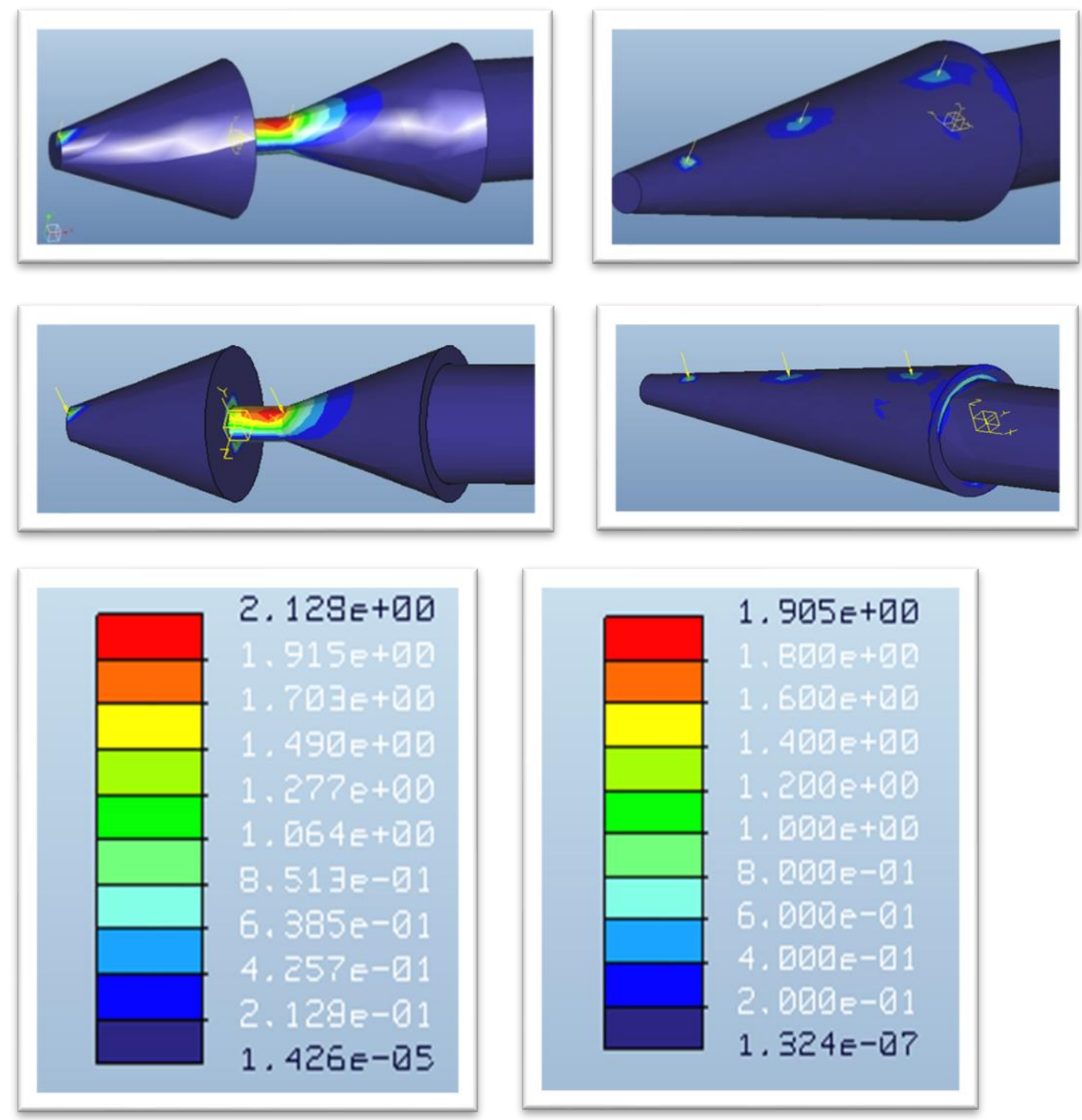

(a) $\operatorname{SDCTP}$ (Former Design)

(b) SCTP (Modified Design)

Figure 9. Juxtaposition of FEA for both Designs for a Specific Case

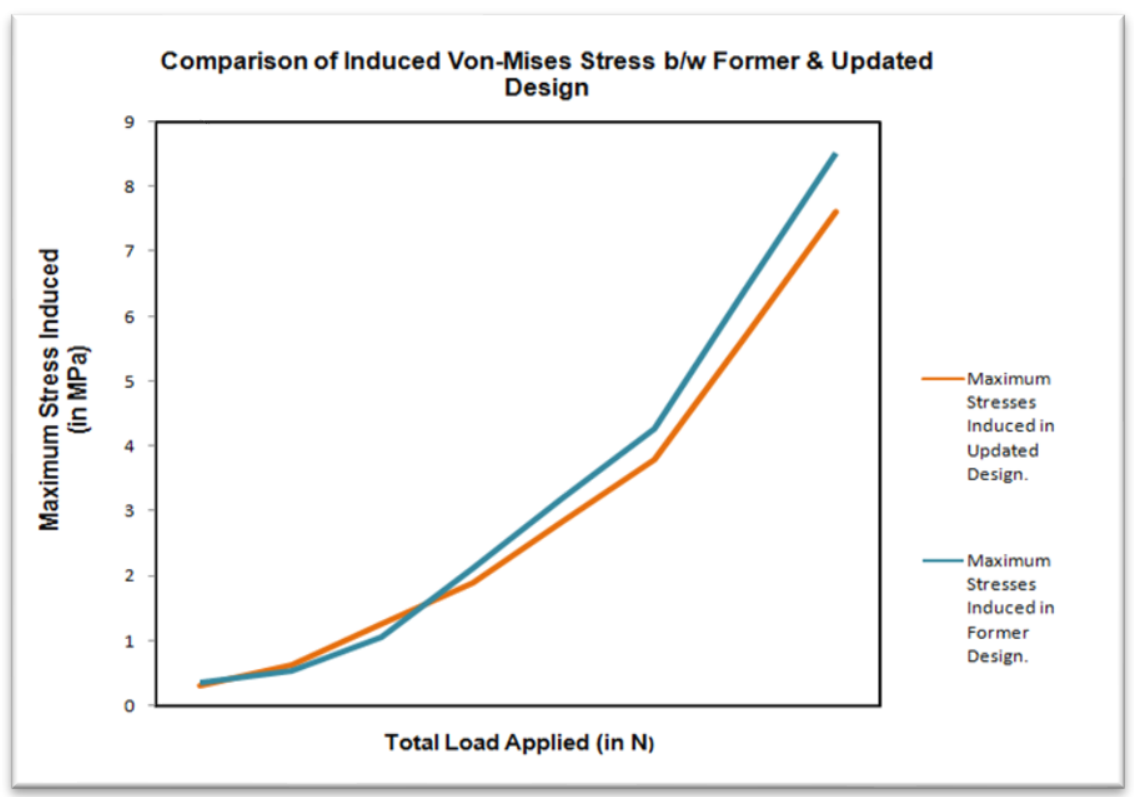

Figure 10. Comparison of induced stress between former and modified design through graph 


\subsection{Grounds for Acceptability of The Modified Design (SCTP)}

The following listed points support the new modified design in accordance to the analyses conducted before its manufacturing.

1. The design of SDCTP had a restriction to place the two tapered cylinders $40 \mathrm{~mm}$ apart due to the design constraints. Violation of this constraint during the manufacturing stage, problem might arise in the tightening of the cutting tool while machining. This problem arises when tool length or tool shank are shorter than $40 \mathrm{~mm}$ in length. In the modified design i.e. SCTP, this problem of tightening of the cutting tool has been worked upon and ceased.

2. The accuracy and precision is more in the modified design (SCTP) in comparison to the former design of SDCTP. The calculations performed for the least count of the cutting tool height lifting (the taper angle is $8.13^{\circ}$ in modified design and $18.43^{\circ}$ in former design), minimum thread engagement length, tensile and shear failure stresses and Von-Mises stresses in FEA for variety of loads were more in favor of the modified design than in former design.

3. Erstwhile design was strenuous to fabricate as in this case the two double solid cones of identical dimensions were required to be manufactured but mechanically two identical things can never be made. Further even a slight difference in the solid cones would lead to number of problems reflecting the effect in the form of surface roughness, poor machining rate, and low MRR etc. In order to overcome this shortcoming, single solid cone was considered in the modified design.

4. In former design i.e. SDCTP, the total load acting on the pin was transmitted to or shared by only two tapered cylinders i.e. at two points only while in modified design i.e. SCTP the same total load is being shared by three tapered cylinders i.e. at three points. This reduces the chances of slipping if the tool shank is of short dimension.

5. As the material at the centre of the tapered portion of threaded pin is more in the modified design as compared to the previous design, the new design of pin is more stable and capable of bearing more stresses before failure. Hence, improving the life of the designed pin i.e. SCTP.

\section{Conclusion}

One of the major concerns in designing the SCTP was size or dimensions as it was required to be placed internally between the lower square plate of tool post and compound rest besides periphery. Secondly a robust construction and wear-less mechanism was needed during the operation so material selection was equally vital as it would also form as the basis for applying load during FEA. After complete survey and review, EN31 steel grade was chosen for manufacturing and mathematical calculations. Through the study of conventional design and literature review, the ranges of turning forces on the cutting tool were known. While machining, cutting force of turning was assumed to be transmitted to the designed pin through the three radial contoured cylinders which are placed on its contour. Further the FEA was performed by considering three point loads acting on the designed component. A comparison of outputs of former design (SDCTP) and modified design (SCTP) was carried out on the basis of least count, thread analysis and FEA. It was concluded that modified design was better in all respects and the cutting tool adjustments became easier and more precise in comparison to the previous design. The lifting of cutting tool by the SCTP further saves time and increases accuracy in alignment of cutting tool tip with the centre of the workpiece which further leads to higher efficiency in machining operation. Hence, the proposed design was manufactured with respect to the calculations and analyses performed. 


\section{References}

Agrawal, B. K. (1988). Introduction to engineering materials.

Ambati, S. Rega, R. (2013). Simulation of cutting stresses and temperatures on tool geometry at the onset of turning operation by finite element method. PARIPEX - Indian Journal of Research, 2, 123-125.

Atkins, A. G. Atkins, T. Escudier, M. (2013). A Dictionary of Mechanical Engineering.

Batni, S. Jain, M.L. Tiwari, A. (2010). Reverse engineering: a brief review. International Journal on Emerging Technologies, 1, 73-76.

Bhandari, V. B. (2012). Design of machine elements.

Bhoyar, Y. R. Kamble, P. D. (2013). Finite element analysis on temperature distribution in turning process using deform-3D. International Journal of Research in Engineering and Technology, 2, 901-906.

Blake, A. (1986). What every engineer should know about threaded fasteners: materials and design.

Bono, M. Hibbard, R. (2007). A flexure-based tool holder for sub- $\mu \mathrm{m}$ positioning of a single point cutting tool on a four-axis lathe. Precision Engineering, 31, 169-176.

Groover, M. P. (2007). Fundamentals of modern manufacturing: materials processes and systems ( $2^{\text {nd }}$ ed.).

Grytskiv, A. Grytskiv, Y. Trofymchuk, A. (2009). Determination of the composition of steels by inductively coupled plasma optical emission spectrometry (ICP-OES) using the thermo scientific icap 6500 duo spectrometer. Chemistry of Metals and Alloys, 177-182.

Gunasekaran, S. Kuppuraj, P. Priya, K. (2014). Determine the chemistry of selected steel by NDE technique of positive material identification (PMI). International Journal of Science and Research, 3, 662-66.

Harms, A. Denkena, B. Lhermet, N. (2004). Tool adaptor for active vibration control in turning operations. Actuator. 9th International Conference on New Actuators, 694-697.

Haughton, M. (2011). Quick change Tool Post-Model engineer workshop manual.

Hou, X. Jonesin, B. T. (2000). Inductively coupled plasma/optical emission spectrometry. Encyclopedia of Analytical Chemistry, 9468-9485.

Jha, N. K. (2015). Green design and manufacturing for sustainability, 307-335.

Kumar, A. Chawla, P. Hitesh, Varshney, S. Bhartiya, M. Lata, S. (2015). Designing of tool uplifting mechanism for four way tool post by reverse engineering. Journal of Material Science and Mechanical Engineering, 2, 80-84.

Kumar, A. Jain, P.K. Pathak, P. M. (2014). Machine element reconstruction using integrated reverse engineering and rapid prototyping approach. 26th All India Manufacturing Technology, Design and Research Conference (AIMTDR), 1231-1235.

Kumar, S. Gupta, M. Satsangi, P.S. Sardana, H. K. (2012). Cutting forces optimization in the turning of UD-GFRP composites under different cutting environment with polycrystalline diamond tool. International Journal of Engineering, Science and Technology, 4, 106-121.

Korka, Z. I. Miclosină, C. O. Cojocaru, V. (2013).An experimental study of the cutting forces in metal turning. UEM, 25-32. 
Lalwani, D.I. Mehta, N.K. Jain, P.K. (2008). Experimental investigations of cutting parameters influence on cutting forces and surface roughness in finish hard turning of MDN250 steel. Journal of Materials Processing Technology, 206, 167-179.

Lathwal, D. Bhardwaj, D. (2013). Study and analysis of single point cutting tool under variable rake angle. International Journal for Research in Applied Science and Engineering Technology, 34-42.

Liu, A. F. (2005). Mechanics and mechanisms of fracture: an introduction.

Lye, P. F. (2014). Metalwork theory book $1 \& 2$.

Mahata, T. K. (2015). Analysis of mechanical and corrosion properties of AISI50110 (EN31) steel with and without heat treatment. International Journal of Future Alloy, 1, 1-12.

Nakra, B.C. Chaudhry, K. K. (2013). Instrumentation, measurement and analysis.

Novotný, L. Blecha, P. (2010). Assessment of design and risk analysis of a tool holder manipulator. Recent Advances in Mechatronics, 389-94.

Ostwald, P. F. Munoz, J. (1997). Manufacturing processes and systems.

Panzera, T. H. Souza, P. R. Rubio, J. C. C. Abrão, A. M. Mansur, T. R. (2012). Development of a three-component dynamometer to measure turning force. International Journal of Advanced Manufacturing Technology, 913-922.

Patil, M. N. Sarange, S. (2014). Numerical analysis to determine the distribution of tool forces and temperatures of single point cutting tool. International Journal of Science and Research, 3,765-71.

Rao, C. J. Rao, D. N. Srihari, P. (2013). Influence of cutting parameters on cutting force and surface finish in turning operation. International Conference on Design and Manufacturing, $1405-1415$.

Rathore, N. Jain, P. K. (2014). Reverse engineering applications in manufacturing industries: an overview. DAAAM International Scientific Book, 567-576.

Rathod, S. H. Mohd. Razik. (2014). Finite element analysis of single point cutting tool. International open access journal of modern engineering research, 4, 12-19.

Sparber, R. G. (2014). A Tool post attachment for a high speed rotary tool.

Thompson, W. B. Owen, J. C. Germain, H. J. Stark, S. R. Henderson, T. C. (1999). Featurebased reverse engineering of mechanical parts. IEEE Transactions on Robotics and Automation, 15, 57-66.

Timings R. L. (1998). Manufacturing Technology ( $3^{\text {rd }}$ ed.).

Tiwari, A. Panchal, N. Solanki, P. Parmar, L. Patel, D. (2014). Designing and fabrication of multipurpose tool post for lathe machine. International Journal for Scientific Research \& Development, 2, 115-117.

Varady, T. Martin, R. R. Cox, J. (1996). Reverse Engineering of Geometric Models - An Introduction.

Vaxevanidis, N. M. Kechagias, J. D. Fountas, N. A. Manolakos, D. E. (2013). Three component cutting force system modeling and optimization in turning of AISI D6 tool steel using design of experiments and neural networks. Proceedings of the World Congress on Engineering.

Wang, W. (2008). Application of reverse engineering in manufacturing industry. 
Wilson, J. D. Hernández-Hall, C. A. (2009). Physics Laboratory Experiments ( $7^{\text {th }}$ ed.).

Yaldiz, S. Unsacar, F. Design, development and testing of a turning dynamometer for cutting force measurement. Mechanical Systems and Signal Processing, 21, 1499-1511.

Yaldiz, S. Unsacar, F. Saglam, H. (2006). Comparison of experimental results obtained by designed dynamometer to fuzzy model for predicting cutting forces in turning. Materials \& design, 27, 1139-1147.

Zhu, W. Jun, M. B. Altintas, Y. (2001). A fast tool servo design for precision turning of shafts on conventional CNC lathes. International Journal of Machine Tools and Manufacture, $41,953-65$. 